\title{
Evolving Korean Parenting Foundations Revealed through Children's Perspectives of East Asian Parenting Beliefs, Styles and Practices
}

\author{
Wendi J. Otto ${ }^{1}$ \\ ${ }^{1}$ Claremont Graduate University, USA \\ Correspondence: Wendi J. Otto, Claremont Graduate University, USA. E-mail: wendiottophd@gmail.com
}

Received: October 24, 2017

Accepted: November 22, 2017 Online Published: December 21, 2017

doi:10.5539/jel.v7n2p34

URL: http://doi.org/10.5539/jel.v7n2p34

\begin{abstract}
Research on parenting styles and children's developmental outcomes have been prominent in the parenting and achievement literature for decades and research shows that parenting style is not consistent across families from diverse backgrounds (Baumrind, 1971; Chao, 1994; Grusec, Goodnow, \& Kuzcynski, 2000). Building on this research, this study examines Korean parenting and its influence on Korean-American achievement by examining the common factors across East Asian parenting ideologies, styles, and practices through the East Asian Parenting Model (EAPM) (Chao, 1994; Choi, Kim, Pekelnicky, \& Kim, 2013; Darling \& Steinberg, 1993) Perceptions about child development and learning and the changing and evolving mother-child relationship are patterns particularly explored in this study. Overall, this study purports important findings regarding evolving Korean parenting foundations affecting Korean-American achievement which add to the field of Asian-American achievement literature. These findings may help inform educators working within school settings about ways in which Korean parenting foundations influence the education of these children.
\end{abstract}

Keywords: Korean achievement, Korean parenting Asian achievement, achievement, Asian parenting

\section{Introduction}

Research on parenting styles and children's developmental outcomes have been prominent in the parenting and achievement literature for decades (Baumrind, 1971; Coleman, 1966; Darling \& Steinberg, 1993; Grusec \& Goodnow, 1994). More recent research shows that parenting style is not consistent across families, especially from diverse ethnic and socioeconomic backgrounds (Grusec, Goodnow, \& Kuzcynski, 2000; Spera, 2006; Steinberg, Lambom, Dornbusch, \& Darling, 1992). Though parenting style is most influenced by cultural value orientation and socialization goals such as educational achievement in Asian-American families (Chao, 1994), data disaggregation on diverse Asian (i.e., East, Southeast) parenting practices as they relate to this achievement is needed, particularly as East Asian students and Korean-American students specifically have emerged as high performers in North America (NCES, 2013).

In fact, Korean-Americans are consistently outperforming other groups including other Asian-American subgroups when the educational attainment rates of Korean-Americans are taken into account along with the data regarding high school courses taken by Asian-Americans as a whole, resulting in Korean-Americans as one of the highest-achieving ethnic groups in North America, with nearly 60 and 50 percent of males and females reporting having earned a Bachelor's degree or higher as of 2011 (NCLB, 2011; NCES, 2013; U.S. Census Bureau, 2013). As a large portion of this achievement has been attributed to Korean-American parents who are reported to have especially high academic expectations for their children due to traditional Confucian values that emphasize academic achievement as the sole means for achieving financial and societal success (Koh \& Shin, 2005; Lim, 2007), what is lacking in the literature on this subject is a body of work which looks at contemporary parenting styles and practices for high-achieving Korean-American students as they relate to academic achievement. Unfortunately, literature which examines such contemporary parenting styles and practices for this population is limited.

\subsection{Purpose of the Study}

The purpose of this study is to examine the common perceptions and differentiating factors regarding East Asian parenting ideologies (parental beliefs about child development and learning and the mother/father-child relationship), styles (parental behaviors that affect the emotional climate of the home), and practices (behaviors 
defined by specific contextual socialization goals, such as techniques of discipline) across high-achieving, Korean-American primary school children via the East Asian Parenting Model. By examining these second-generation children's perceptions across these parenting ideologies, styles, and practices, it may be possible for those involved in the education of Korean-American children to learn of the differentiating factors (i.e., specific East Asian parenting ideologies) that may be influential for explaining the Korean parenting foundations influencing the academic achievement in these children.

\subsection{Background and Literature Review}

The role that culture plays in the Asian family must be understood in order to contextualize the family practices within Asian families compared to those within Western ones. Along these lines, there is tremendous diversity within the Asian race as identified by the subgroups in this category according the U.S. Census Bureau (U.S. Census Bureau, 2012).

The cultural emphasis on interdependence within the family amongst its members is a predominant Asian family trait which begins early in childhood and is complimented by a set of unifying principles called filial piety which underlies the interdependence and acts as a guiding philosophy governing patterns of socialization as well as specific rules about intergenerational conflict in Confucian Asian families (Chao, 1994; Chao \& Tseung, 2002; Lee, 1996). As such, it is the East Asian Confucian concept of filial piety that further emphasizes the children's actions do not just simply have ramifications for themselves but their actions can bring honor and pride or dishonor and shame to the entire family (Kim \& Park, 2006; Koh \& Shin, 2005; Larson \& Lee, 2000).

Also in the Asian family, authority and responsibility are divided and deferred to among certain family members through role relationships and reciprocity, the complimentary characteristics to interdependence, where different family members fulfill different roles with an overall family system of reciprocity, defined by caring and mutual obligation. Hence, parents and other elders within the Asian family hold considerable authority and responsibility and are then treated with great respect by the children (Lee, 1996). Yet, the parental authority that parents and various other family members hold within the Asian family is misunderstood in Western thought. In other words, the Asian cultural frameworks which emphasize interdependence among family members suggest that the parental authority that Asian parents exert over their children reflects a strong family system and proves strong parental love and concern, opposite of some Western frameworks and literature on the topic which characterize this parental authority as harsh and stifling (Baumrind, 1971; Kang, 2002; Larson \& Lee, 2000).

\section{Parenting Style and East Asian Parenting}

It was Baumrind (1971) who documented and developed the four distinct different styles of parenting - the authoritarian, the authoritative, the permissive, and the neglectful — of which the authoritative style of parenting has been accepted as the ideal means for socializing children for the internalization of parental values and goals in the United States. This seminal work posted that the parents who develop positive relationships with their children by being firm, not overly controlling, and relying more on reasoning and persuasion than by use of power will have more success in the socialization of their children in any particular given context, particularly educational settings (Baumrind, 1971). Research on this topic was extended in the 1980s and 1990s to examine parenting practices along with parenting style on the achievement of children from various ethnic groups (Steinberg et al., 1992). This work posted that children of different ethnic groups may respond positively to different parenting styles and practices which affect achievement, thus beginning a new academic discourse regarding the influence of parenting on the achievement of diverse groups.

This discourse continues in the form of achievement literature utilizing theoretical models which incorporate parenting beliefs, style, and practices within the home environment as influential factors affecting the academic achievement of children from diverse backgrounds. In other words, this same literature suggests that in order to better understand the socialization processes of children, it was important to distinguish between parenting style and practices and operationalize both terms in the literature on the home factors (parental values and goals which drive the parenting style and practices) which can influence the academic achievement in children (Darling \& Steinberg, 1993; Grusec, Goodnow, \& Kuzcynski, 2000; Steinberg et al., 1992).

As such, parental ideologies (parenting beliefs, values and goals) are critical factors influencing the home environment and in the Korean culture, the uncompromised value of academic achievement for the children appears to be highly influenced by the Confucian and familial values of their Korean parents (Akiba \& Zhao, 2009; Paik, 2008; Park, 2007; Shin \& Yang, 2008; Sorensen, 1994). As a result, the high academic outcomes for students of Korean ethnicity on U.S. national exams suggest that the parenting ideologies (parental beliefs and practices about child development and learning and the mother-child relationship) which guide the child-rearing 
experience for East Asian (including Korean) parents strongly affect achievement (Choi, Kim, Kim, \& Park, 2013; Choi, Kim, Pekelnicky, \& Kim, 2013; Chao, 1994).

More recent literature on the use of culturally appropriate parenting measures further validates the use of Chinese East Asian parenting ideologies (beliefs about child development and learning and the mother-child relationship) as culturally appropriate for use as Korean parenting measures (Choi et al., 2013). Specifically, the Korean parenting measure of Ga-jung-kyo-yuk (translated as "home [or family] education") is closest in concept to "family socialization" or "family processes" for purposes of socializing children to a set of core norms, beliefs, and values through parenting, though some differences do exist between Chinese and Korean norms, beliefs, and values.

The core values of ga-jung-kyo-yuk include emphasis on parenting via role-modeling, the centrality of the family, family hierarchy, demonstration of respect for and the use of appropriate etiquette with parents and elders, age veneration, and family obligations and ties includomg child-rearing practices. Three recently developed measures-Korean traditional parent virtues, enculturation of familial and cultural values, and important Korean traditional etiquette - mostly measure parental values (Choi et al., 2013). Conversely, the EastAsian parenting ideology about the mother-child relationship measures and evaluates specific behaviors of parental control and warmth (Chao, 1994). Because the value measures assess cultural beliefs and ideals, Choi et al. (2012) found that the measures were positively correlated with authoritative parenting, parental warmth, and acceptance and that the behavioral measures within the same parenting idelogy were also significantly and positively correlated with the ga-jung-kyo-yuk value measures, demonstrating a possibility that ga-jung-kyo-yuk behavioral measures may also overlap with ga-jung-kyo-yuk value measures. As a result, the most recent literature regarding culturally approriape parening measures for Korean parenting compared ga-jung-kyo-yuk and Western parenting style and found that the existing scales for the East Asian parenting ideology about the mothrt/child relationship and its complimentary East Asian idology about child development and learning did indeed work properly and were thus recommended for use with Korean immigrant and Korean American parents (Choi Y., Kim, Pekelnicky, \& Kim, 2013).

East Asian Beliefs about Child Development and Learning. It has been found that children learn to adopt the East Asian parental beliefs of motivation and filial piety by being trained early to work very hard and be disciplined, though this may involve the parents pushing the children when motivation is not adequate. In fact, East Asian children have extensive experiences of what is expected in terms of their behavior from a very young age, as they are usually in the company of adults and exposed to models of proper (academic and other) behavior as well as many aspects of the adult world very early in life (Chao, 1994; Chao \& Arque, 2001).

Shifting Western discourse in terms of parenting style, Chao (1994) confirmed that Chinese parents, and by extension Korean parents as correlated by Choi (2013), believe that: (1) parents must begin training child as soon as ready ( $M=4.48$ Chinese, 2.30 Euro-American), (2) children can improve in almost anything if they work hard ( $M=4.32$ Chinese, 3.90 Euro-American), (3) the best way child learns how to behave is to be around adults ( $M$ =3.16 Chinese, 2.20 Euro-American), and (4) when a child continues to disobey you, he/she deserves a spanking ( $M=3.22$ Chinese, 1.48 Euro-American). These comparisons of childrearing beliefs among immigrant Chinese and Euro-American mothers provided a contrast between parenting for interdependence versus independent goals. For example, which a Korean-American child fails to meet their parents' expectations regarding academics or other behavioral outcomes; the usual intense parental attention would most likely be replaced by strict sanctions and more control in order to bring the children back into line with the goals and values of the family (Shin \& Yang, 2008).

Research also suggests that life rapidly changes when Korean children enter school, s these children are now expected to follow rigid codes of behavior and adhere to strict disciplinary standards (Chao, 1994; Shin \& Yang, 2008). Moreover, as the Korean culture emphasizes group awareness, sensitivity to others, and the minimization of conflict over individual concern, the primary goals within the East Asian belief about child development and learning are that the parents are to teach the children to learn self-control, develop an interdependent sense of self, and foster cooperative and prosocial behaviors (Farver, Kim, \& Lee, 1995).

In this respect, Korean parents try to do their best to give their children every opportunity for a better life; yet, what constitutes a better life differs in Eastern and Western cultures and is a matter of opinion to what degree the power is wielded by parents to "train" their children in the proper behaviors to ensure such a life (Kang, 2002). However, there is little room for children's opinions in this East Asian parenting ideology, as Korean children are the objects of their parents' love and their sole purpose in life - and as such are expected to be obedient followers of their parents (Chao, 1994). 
East Asian Beliefs about the Mother-Child Relationship. Literature in the field has continually reported that the Korean mother largely facilitiates the filial piety and parental authority within the family, especially in the child's early years. During this time, the East Asian (Korean) mother is reported to provide an extremely nurturing environment for the child by being physically available and by promptly attending to the child's every need. She has also been reported to provide the support and drive for the school-age children to achieve in school and ultimately meet the societal and familial expectations (Chao, 1994; Choi et al., 2013; Wu, 1985; Young, 1972). Further shifting Western discourse regarding parenting styles, Chao (1994) also confirmed and Choi (2013) also agreed that Chinese (and Korean) parents believe that: (1) mothers primarily express love by helping children succeed, especially in school, (2) children should be in the constant care of their mothers, (3) mothers should do everything for children's education and make many sacrifices), and (4) children should be allowed to sleep in the mother's bed. These findings are fundamental in understanding the Korean mother-child relationship and how these beliefs influence and shape the Korean mother-child patterns of behavior.

Because the Korean mother and her child share a "we" identity socially and the family shares a sense of accomplishment culturally, Korean mothers have also been known to morph into an intensified role of "educational manager mother" to facilitate her children's education while utilizing culturally appropriate guilt and external pressure to further serve as additional motivational factors (Park, 2007). Though Koreans are known to believe in the "age of innocence" (the inherent goodness of children) (p. 65) and hold protective attitudes for their children early in life, once the children enter formal schooling those parental attitudes change to expectations of following rigid codes of behavior and strict disciplinary standards based upon the hierachical nature of Korean culture and society (Chao \& Tseung, 2002). In other words, once the children enter kindergarten, the honeymoon is over as the children's lives and decisions are firmly under parental control and the "swish of the skirt" (Park, 2007, p. 189) of the Korean educational manager mother begins (guan). As such, these interactions between the East Asian parenting beliefs about child development and learning and the mother-child relationship help explain the academic success of Korean-American students (Bong, 2008; Chao, 1994; Kim \& Park, 2006: Schneider \& Lee, 1990).

The Father-Child Relationship. Interestingly, East Asian parenting literature contains minimal information on the role the Korean father plays in the children's education as Asian fatherhood research is still in its formative stages (Shin \& Yang, 2008; Yang \& Rettig, 2003; Yeung, 2013). Though the role of the father in Asian families may be changing, patriarchy remains a dominant family ideology in many Asian societies that may inhibit the emergence of the "new father" in these families, despite an increase in Asian women's education and labor force participation (Yeung, 2013).

Research on family change predicted a convergence between Western and developing countries to a conjugal family form in which marriage bonds rather than lineage bonds would become more prevalent and that marriages based on a companionate relationship would become the norm (Goode, 1963, as cited in Yeong, 2013). Indeed, much of this general trend has occurred in varying degrees in many Asian societies; however, diverse cultures, socioeconomic and political structures, and policies and programs across Asian countries have also shaped family values and behaviors in ways that are distinct from what we see in contemporary Western society, including how men view fatherhood and how fathers relate to their children and spouses.

In his most recent work, Yeung (2013) reports that Western fathers' involvement in child-rearing (both in absolute and relative terms) has increased despite a considerably lower level of physical involvement in such activities as compared to mothers because there is a heightened expectation of "new fathers" to provide more physical and emotional care to children in addition to the financial resources already expected. Yet, though time use research suggests that the Asian fathers' involvement level is likely to be lower than men in Western societies despite Asian women's equally high participation in the labor market, these fathers may play a greater role in their children's education in achievement related matters than they have been reported to before (Shek, 2006; Won \& Han, 2010; Yeung, 2013).

\section{The School-Home Connection}

And so it goes - children all over the world, regardless of ethnicity, spend a large majority of each day at school interacting with teachers, peers and school administrators. As a result of these activities, the school and the home environments are suggested to be the two most important developmental contexts for children and adolescents because of the interactions between the children and multiple primary socializing agents within these contexts (e.g., parents, teachers, and peers) (Hong, Milgram, \& Perkins, 1995; Steinberg et al., 1992). Thus, the school and home contexts gain critical importance as children mature and begin the transition from a highly dependent 
and controlled period of childhood into one of self-exploration in which children begin to consider their connections to family, friends, and society.

This time can also begin a time of challenge and change for a majority of family units, as the formal operational stage of childhood is when children develop ideas and hypotheses, set individual goals, define interests, and reflect on their relationships with and responsibilities to others while concurrently trying to respond to the needs and wishes of their parents (Piaget, 1952). Thus, during this time all children begin to form and adopt for themselves their own goals, values, and attitudes related to school while being simultaneously influenced by their parents to achieve, adopt, and manifest certain goals and attributes valued by the family (Darling \& Steinberg, 1993; Goodenow \& Grady, 1993). This can become quite a challenge for Korean-American children, as they attempt to negotiate their own developing personal goals and values regarding school with those of their first-generation parents (Noyot-Corbitt \& Moon, 2010; Steinberg et al., 1992).

\subsection{Theoretical Framework}

The theoretical framework for this study is based on the earlier work of Baumrind (1971), Chao (1994), and Darling \& Steinberg (1993), whose models were selected to serve as the basis for the formulation of the theoretical framework for this study because each framework alone is insufficient to fully explain Korean-American achievement within the context of parenting. Therefore, the model builds upon these seminal frameworks by extending Chao's (1994) Chinese parenting style model (who extended Baumrind's (1971) Western parenting conceptualizations) and Darling \& Steinberg's (1993) constructs of parenting styles and practices to form the EAPM (East Asian Parenting Model), a new framework which seeks to explain Korean-American achievement through the interactions between East Asian parenting ideologies (beliefs), styles, and practices.

The EAPM builds upon the Chinese (or East Asian, hence Korean) Cultural Notion of Training developed by Chao (1994) in response to the "authoritarian" (controlling and restrictive) parenting style concept developed by Baumrind (1971) and completely misunderstood in the recent, yet controversial, book entilted Battle Hymn of the Tiger Mother popularized in Western educational circles (Chua, 2011). The EAPM also incorporates the Contextual Parenting Style model developed by Darling \& Steinberg (1993) to investigate the lack of understanding of ethnic differences in Western Euro-parenting research. Thus, the EAPM posts that the East Asian parenting ideologies of chao shun and guan (child-rearing beliefs and practices about child development and the mother/father-child relationship) from Chao's (1994) model and deemed appropriate for use with Korean immigrants and Korean Americans because of its simillarites to ga-jung-kyo-yuk (Choi, Kim, Pekelnicky, \& Kim, 2013), influence both the parenting style (the emotional climate in which parental behaviors are expressed) and parenting practices (behaviors defined by specific contextual socialization goals, such as techniques of discipline) from Darling and Steinberg's model (1993), all which directly affect the developmental outcomes of the children (for purposes of this study, the academic achievement of Korean-American children.).

Drawing from Chao's (1994) Eastern model of child-rearing through the Chinese concepts of chiao shun (teaching or training children in the proper and expected societal behaviors) and guan (control and governance) and their impact on the academic success of Chinese students, the EAPM presents an extended framework for East Asian school success while rejecting Baumrind's (1971) parenting style conceptualizations (authoritarian, authoritative, permissive and neglectful) as ethnocentric in the same fashion as Chao (1994) and Darling \& Steinberg's (1994) parenting models and posts that the Western concepts of authoritative and authoritarian do not capture the important features of East Asian (including Korean) parenting ideologies, styles, and practices, especially when explaining for school success (Chao, 1994).

As such, the EAPM draws upon the simultaneous parental utilization of chiao shun and guan as complimentary foundational values for academic achievement for Korean-American children and argues that the Chinese concepts of chiao shun and guan must be understood from an indigenous (Eastern) perspective in order to fully understand the workings of the EAPM (Chao, 1994; Darling \& Steinberg, 1993; Ho \& Kang, 1984; Wu, 1985).

As this is a qualitative study, a "broad" interpretation will be used for the cause and effect relationship in the model. Therefore, the model will consider four individual factors: 1) children's perceptions of their parents' East Asian ideologies about child development and learning (chiao shun), 2) children's perceptions of their parents' East Asian ideologies about the mother/father-child relationship (guan), 3) children's perceptions of East Asian parenting style, and 4) children's perceptions of East Asian parenting practices. The developmental outcome is Korean-American academic achievement. See Figure1. 


\subsection{Research Questions}

The overarching research question guiding this study, therefore, is: What are the common factors (East Asian parenting ideologies, styles, and practices) across high-achieving, Korean-American children?

Specifically,

1) What are the common factors across East Asian ideologies about child development and learning (chao shun) based on the perceptions of high-achieving, Korean-American children?

2) What are the common factors across East Asian ideologies about the mother/father-child relationship (guan) based on the perceptions of high-achieving, Korean-American children?

3) What are the common factors across East Asian parenting style based on the perceptions of high-achieving, Korean-American children?

4) What are the common factors across East Asian parenting practices based on the perceptions of high-achieving, Korean-American children?

5) What are the common factors across East Asian parenting ideologies, styles, and practices based on the perceptions of high-achieving, Korean-American children?

\section{Method}

\subsection{Methods \& Design}

Method: This study utilized a qualitative design to explore the common factors across high- achieving, second-generation Korean-American primary school children based upon the perceptions of their parents' East Asian parenting ideologies, styles, and practices. Creswell (2009) states that a qualitative methodology is appropriate where the research looks into the complexity of participants' experiences and how the meanings they make of these experiences (perceptions) shape their beliefs and actions.

Sample. A purposive, snowball sample of second-generation, Korean-American, high-achieving, primary children ( $\mathrm{N}=40$-total) was utilized. Children's perceptions, as opposed to parental ones, were critical for this study as "the perception of parent style by the child is more important than actual parenting" (Steinberg et al., 1992, p. 32). Primary students in grades four through six were selected to be used for this study because pre-adolescent children are primarily influenced and controlled by family at this age rather than by outside influences such as negative peers (Moon \& Morash, 2004; Morash \& Moon, 2007; Noyot-Corbitt \& Moon, 2010). High academic achievement was verified for each study participant via standardized state English/Language Arts and Mathematics test score reports.

Protection of Human Subjects. This study received full IRB approval.

\subsection{Data \& Data Analysis}

Data. The measurement tool is one semi-structured interview (Appendix A). Questions from Parts I and II were adapted from the methods section of Chao's (1994) Chinese parenting model. Questions from parts III and IV were adapted from the Parental Authority Questionnaire (Buri, 1991) which measures parenting style and practices based on Baumrind's (1971) parenting conceptualizations: authoritarian, authoritative, permissive and neglectful. The authoritarian style and practices statements were identified and modified to fit the EAPM framework.

Data Analysis. Data underwent a content analysis process. As a first step, participant statements were separated by question as the author read each transcript line by line and wrote down short, descriptive statements or quotes from each statement into Microsoft Word tables. With this accomplished, summarizing statements were created to best interpret their meaning after which each summary was coded by theme according to the constructs of the EAPM. Then, all codes across participants were read together for emergent patterns and themes on student perceptions about their parents' East Asian parenting beliefs about child development and learning, the East Asian mother-child relationship and East Asian parenting styles and practices, culminating in a total number of 17 results tables for Sections I, II, III, and IV of the structured interview (Appendix A). Please contact the author for a full set of results tables.

\section{Results}

The purpose of this study is to provide a theoretical and empirical basis for understanding second-generation children's perceptions across East Asian parenting ideologies, styles, and practices via the East Asian Parenting Model, which proposes an intersection of achievement which may be influential for explaining the Korean parental ideologies responsible for such achievement. See Figure 2. 
RQ \#1: What are the common factors across East Asian ideologies about child development and learning based on the perceptions of high-achieving, Korean-American children?

These findings, as they relate to academic achievement, are consistent with the East Asian concept of chao shun in that the overwhelming majority of parents are perceived to believe that children must be trained $(92.5 \%)$ by age $5(39 \%$ of the $92.5 \%)$ in the proper behaviors $(29 \%$ of the $92.5 \%)$ and that children can improve in almost every situation $(95 \%)$ through effort $(31 \%$ of the $95 \%)$ and hard work $(46 \%$ of the $95 \%)$. Though not an overwhelming majority, the majority $(58 \%)$ of the study participants perceive their parents to prefer their children be in the company of adults rather than in the company of other children to monitor or teach proper behavior ( $41 \%$ of the $58 \%$ ) and to limit exposure and/or the influence of negative peers $(41 \%$ of the $58 \%)$.

Though the majority of the parents do spank ( $72 \%$ of the 54 total responses), less consistent are the students' perceptions about the reasons for parental spanking, reporting to be spanked for behavioral reasons (31\%) and/or moral shortcomings (30\%). A solid 19\% of study participants report their parents to not believe in spanking under any circumstances.

RQ \#2: What are the common factors across East Asian ideologies about the mother/father-child relationship based on the perceptions of high-achieving, Korean-American children?

These findings, as they relate to academic achievement, are consistent with the East Asian concept of guan in that the majority of study participants perceive a physically and emotionally close relationship with their mother through multiple responses about emotional support, physical affection, health and wellness $(24 \%$, $23 \%$, and $22 \%$ of 97 responses, respectively) and sleeping arrangements, with 33 out of the 40 study participants (83\%) reported to having slept with their mothers at least up through the ages of three to seven. However, results are less consistent for the care-giving and sacrificial roles of the mother within this parenting ideology.

\subsection{Maternal Care-Taking}

Table 1. Children's responses to Question \#6: "Do your parents feel that it is only the mother's job to take care of the children in a family? (i.e., making all meals, transportation arrangements, no babysitters or daycare)?" Explain

\begin{tabular}{lll}
\hline Codes & No. of Responses & Percent \\
\hline No & 35 & 87 \\
\hline Yes & 4 & 10 \\
\hline Declined & 1 & 3 \\
\hline Total & 40 & 100 \\
\hline
\end{tabular}

\begin{tabular}{llll}
\hline No Codes & Examples & No. of Responses & Percent \\
\hline Mom + Dad & & 16 & 38 \\
Mom + Extended family & Grandma, older siblings & 10 & 24 \\
Child advocates for mother & Acknowledges mom's need for help as a parent. & 10 & 24 \\
Mom + close friends & Friend's parents & 5 & 12 \\
Mom + babysitters & & 1 & 2 \\
\hline Total & & 42 & 100 \\
\hline
\end{tabular}

Note. Some participants reported multiple responses.

Notice that 10 out of the 42 responses (24\%) advocated for the mother when answering this question, acknowledging how difficult it is taking care of the children in a family and that mothers need assistance with this task, interjecting their own opinions into their responses.

Bob Tunes: "She can get stressed out, so sometimes dad cooks and I do the dishes and laundry....It's not only just her job. [Sometimes] Grandma helps too." Brandon (pseudonym): "No, because my mom doesn't take care of us the whole time. My dad usually takes care of us...they should have equal rights and priorities (sic) to take care of us." Bob Lee: "A mother can take another interest other than just taking care of the children... [sometimes] they would like to spend time for themselves."

Still though, four participants out of the sample of $40(10 \%)$ perceived their parents adhering to traditional East Asian gender roles within the family as they pertain to the mother-child relationship. Elizabeth (pseudonym) explains, "Yes. Dad says when he does something that's not what women should do...you shouldn't act like 
men...my dad says mom should do because he's busy, but mom's busy, so she sometimes asks my sister." See Table 1.

\subsection{Maternal Sacrifice}

Table 2. Children's responses to Question \#7: "Do your parents feel that mothers should sacrifice everything for a child's education? (i.e., no outside career or all money earned spent only for tutors or tuition)? You know this how?"

\begin{tabular}{lll}
\hline Codes & No. of Responses & Percent \\
\hline No & 18 & 45 \\
Yes* & 10 & 25 \\
Undecided/question misunderstood & 7 & 18 \\
Question declined & 5 & 12 \\
\hline Total & 40 & 100 \\
\hline
\end{tabular}

Note. *though 3 participants strongly disagree with this parental value.

\begin{tabular}{lll}
\hline No Codes & No. of Responses & Percent \\
\hline Mom spends money elsewhere & 8 & 44 \\
Parents hold additional objectives for the children & 5 & 28 \\
Parents should both sacrifice & 3 & 17 \\
Child must assume personal responsibility for education & 2 & 11 \\
\hline Total & 18 & 100 \\
\hline
\end{tabular}

Participant responses for this question were quite mixed and varied the most in terms of responses and percentages out of any other question in the interview protocol in this study. Nearly half (18 out of the 40 participants) perceived their parents to not believe in or practice this East Asian parenting ideology because of perceptions about finances (eight participants out of the 18), parental goals and roles (eight participants out of the 18), and responsibilities of the children (two participants out of the 18). Also, seven out of the 40 participants $(18 \%)$ did not even understand the question after several clarifications. This is the largest percent of study participants not understanding any construct in the entire interview protocol.

Though 10 out of the 40 participants (25\%) perceived their parents to agree with this ideology, three of these 10 participants strongly disagreed with their parents' point of view and clearly interjected their oppositional opinions into their responses to this question. Eundo explained, "My parents want me to grow up and be strong, smart, and educated....But I say no because I don't want them [mom and dad] to sacrifice everything but they'll say yes because they want me to get educated." Daniel (pseudonym) felt the same. "I think mom would say yes", he responded to the question. "But I think she should do for herself too." Jess was the last to advocate. "I think my mom would, but I wouldn't want her to be," she said about her mother. "I want her [to] live, like her own life. I wanna (sic) tell her that I can do things by myself now and just take care of her and not worry about me." See Table 2.

\subsection{Paternal Academic Involvement}

Table 3. Children's responses to Question \#9:" In what ways does your father play a role in your education? (i.e., parent conferences, homework?)

\begin{tabular}{llll}
\hline Codes & Examples & No. of Responses & Percent \\
\hline Helps with school work & Teaches, monitors homework & 21 & 37 \\
\hline & Attends conferences, donates & & 37 \\
\hline Other school assistance & supplies, signs paperwork & 21 & 18 \\
\hline Provides financial support & Pays for tutors/tutoring & 10 & 7 \\
\hline No response/no role & & 4 & 1 \\
\hline Provides discipline & & 1 & 100 \\
\hline Total & & 57 & \\
\hline
\end{tabular}

Note. Some participants reported multiple responses. 
The final question in Section 1I of the semi-structured interview investigated children's perceptions about the role their father plays in their education to which participants reported mixed and multiple responses. For the most part, study participants perceived their fathers to play a supportive role in their education through helping with school work, providing other school assistance, and supplying the financial support to pay for it all (37\%, $37 \%$, and $18 \%$ of responses, respectively). Four study participants percieved their father as having no role in their education because they were from divorced households reporting no relationship with their fathers at all and one participant declined to even answer the question. Only one study participant perceived providing discipline as the manifestation of their father's role in their education.

Ruby: "My dad's a teacher. He teaches me every step of the way. Spelling, writing, social studies, science—all the way up to now."

Amanda (pseudonym): "He helps me with my spelling test and if my tutor doesn't come that day....and if I get it right he makes me really happy so I want to work harder....[he's] supporting."

Bob Jr.: (pseudonym): "He supplies pictures for the school, does (develops) all my teacher's pictures, attends conferences and pays for tutor."

Bob Smith (pseudonym): "He signs stuff."

Alice (pseudonym): “[He] pays for all the things I do, teaches me some of the things I don't know....[He] compliments me and that makes me want to work harder."

PI: "Does he also attend parent/teacher conferences?

Alice: "Most of them."

Although study participants reported varying degrees of this academic assistance, the author of this study coded only the responses regarding the assistance itself and not according to perceived time spent on such assistance. See Table 3.

RQ \#3: What are the common factors across East Asian parenting style based on the perceptions of high-achieving, Korean-American primary school children?

These findings, as they relate to academic achievement, are consistent with the East Asian parenting and achievement literature in that the overwhelming majority of the study participants perceived themselves as not having any say in parental educational decisions ( $88 \%$ of responses) though the majority of study participants perceived a positive emotional climate in their homes (55\% of responses). Also consistent with this same literature are the reports by study participants who perceived negative parental responses if opposition to parental decisions is voiced (55\% of responses). The responses also include swift and firm reactions from their parents when parental expectations are not met ( $74 \%$ of responses).

RQ\#4: What are the common factors across East Asian parenting practices based on the perceptions of high-achieving, Korean-American primary school children?

These findings, as they relate to academic achievement, vary. Only about one-third of the study participants perceived their parents as utilizing educational practices on them "for their own good" (39\% of responses), through the study participants were expected to comply with parental requests within five minutes $(67.5 \%$ of responses). A large number of study participants also reported that they perceived their parents teaching them how to behave institutionally as well as publicly through explicit behavioral directions (57\% of responses) and over one-half of the responses reported by study participants (54\% of responses) perceived their parents to have and utilize social capital for their educational needs through the utilization of available resources and friends (31\% and $23 \%$ of responses, respectively).

RQ \#5: What are the common factors across East Asian parenting ideologies, styles, and practices based on the perceptions of high-achieving, Korean-American children?

Answers which yielded over 50 percent of responses for any of the semi-structured interview questions for each construct within the theoretical model are considered to be the common factors across high-achieving Korean-American children. These common factors, as they affect academic achievement, are consolidated into Figure 3.

The common themes which were found to affect the intersection of high achievement for this group within the parenting ideology about child development and learning were that the majority of the study participant perceived their parents to (1) believe in children's early training (learning to be self-controlled and behave properly) by the age of 5, (2) the effort model for learning, (3) the preference for children to be in the company 
of adults for purposes of behavior modeling, and (4) spanking for behavioral reasons or moral misbehavior is appropriate, suggesting that the East Asian parenting ideology of chao shun currently informs the intersection of achievement for Korean-American high-achieving children.

More common themes which were found to affect the intersection of high achievement for this group within the parenting ideology about the mother/father-child relationship were that the majority of the study participants commonly perceived their parents to believe in mothers having extremely close emotional and physical relationships with their children including, but not limited to, sleeping in their mother's bed beyond the age of early childhood. The currently study also found that fathers have now been included in this construct, differentiating the EAPM from other East Asian achievement and developmental frameworks, as fathers are commonly perceived by the majority of the study participants as assisting with school through active participation and to be present in their lives, suggesting that at least part of the East Asian parenting ideology of guan also currently informs the intersection of achievement for these children.

Furthermore, the EAPM proposed that the parenting ideologies of chao shun and guan would influence the parenting styles and practices utilized on the study participants forming intersection of high achievement for their children. Thus, the common themes found to affect this intersection regarding East Asian parenting style and practices were that the study participants commonly perceived their parents to believe in providing a happy and comfortable home for them where the parents served as primary decision-makers, whose expectations regarding their children were to be met as best they could and that the study participants commonly perceived their parents to provide explicit institutional and public behavioral directions and expected parental requests to be responded to immediately, respectively.

The care-giving and sacrificial roles of the mother, parental practices done for the child's "own good", and parental social capital utilization patterns were not found to be common factors across high-achieving, Korean-American children affecting achievement, as all four of these factors yielded no clear majority response from the study participants. Therefore these factors were not included in the intersection of achievement and were not included in Figure 3.

\section{Discussion and Conclusions}

The East Asian parenting model predicts that when all the common factors presented in Figure 3 regarding student perceptions of their parents' East Asian parenting ideologies, styles and practices are present, achievement will be high for Korean-American second-generation children. As the results of this study suggest, this model serves well to explain the high achievement of this particular group, as 13 out of the original 17 EAPM factors explored in the interview protocol were found to be common to form an intersection of achievement.

The overall results also suggest that the EAPM can inform those involved in the education of Korean-American children of the differentiating factors across the East Asian parenting ideologies of chao shun and guan and the East Asian parenting style and practices that may be influential for explaining the Korean parenting foundations responsible for the academic achievement of the children in this group. These common perceptions can inform teachers and teacher candidates as to an explanation of why the Korean-American children in their classrooms perform so well and can also provide insight into the Korean parenting dynamic, a dynamic far different than that suggested in Western academic discourse (Chao, 1994; Steinberg, Lambom, Dornbusch, \& Darling, 1992).

However and perhaps even more importantly, hius study purports other important findings regarding the factores affecting Korean-American achievement which add to the field of Asian-American achievement literature. In particular, these secondary findings suggest (1) contemporary adherence to the traditional foundational East Asian cultural and Confucian beliefs about child development and learning (chao shun) and (2) partial adherence to the complimentary beliefs about the dynamics of the East Asian mother-child relationship (guan) by Korean parents as perceived by their Korean-American children, suggesting that the East Asian guan parenting ideology is adapting to American acculturation via changing paternal roles for the Korean mother as well as for the Korean father within the contemporary Korean-American family. This is an important new piece of research, as the adaptation of the guan ideology to American acculturation is a clear departure from Chao's (1994) findings a generation ago, suggesting a need for an alternate definition of guan in contemporary Korean parenting ideological foundations.

In conclusion, what those involved in the education of second-generation Korean-American children need to understand is that the findings from the current study strongly suggest that the East Asian cultural and Confucian beliefs about child development and learning (chao shun) and the close dynamics of the East Asian mother-child relationship, combined with the emerging, active relationship of the "new" Korean father (evolving definition of 
guan), serve as developmental foundations for the child; foundations on which the child is both physically and mentally "trained" to accept through both the controlling yet supportive East Asian parenting style and the strict behavioral practices designed to result in Korean-American academic achievement.

\section{Implications}

The EAPM posts that the East Asian ideologies of chao shun and guan are both foundationally responsible for influencing the high achievement of Korean-American children and the results of this study suggest that this achievement occurs despite the guan ideology (including the role of the Korean father) adapting to acculturation. Future research could benefit from a further exploration of an alternate definition of guan as one that substitutes the sacrificial and care-giving roles of the Korean mother for the active participation of the father and other immediate and extended family members and the role this alternative definition plays in the academic achievement of Korean-American children; possibly in terms of an East Asian American Parenting Model (EAAPM) which utilizes this new definition of guan as a foundational ideology for Korean-American achievement. Such research in addition to the results of the current study may help inform educators working within school settings about ways in which foundational parenting ideologies influence the education of Korean-American children. Lastly, as the EAPM is cultural in nature with no structural fcets, the author cautions its use to frame the (non)aciievemtnt of other cultural groups as its application may lead to suggestions of cultural deficit.

\section{East Asian Parenting Model (EAPM)}

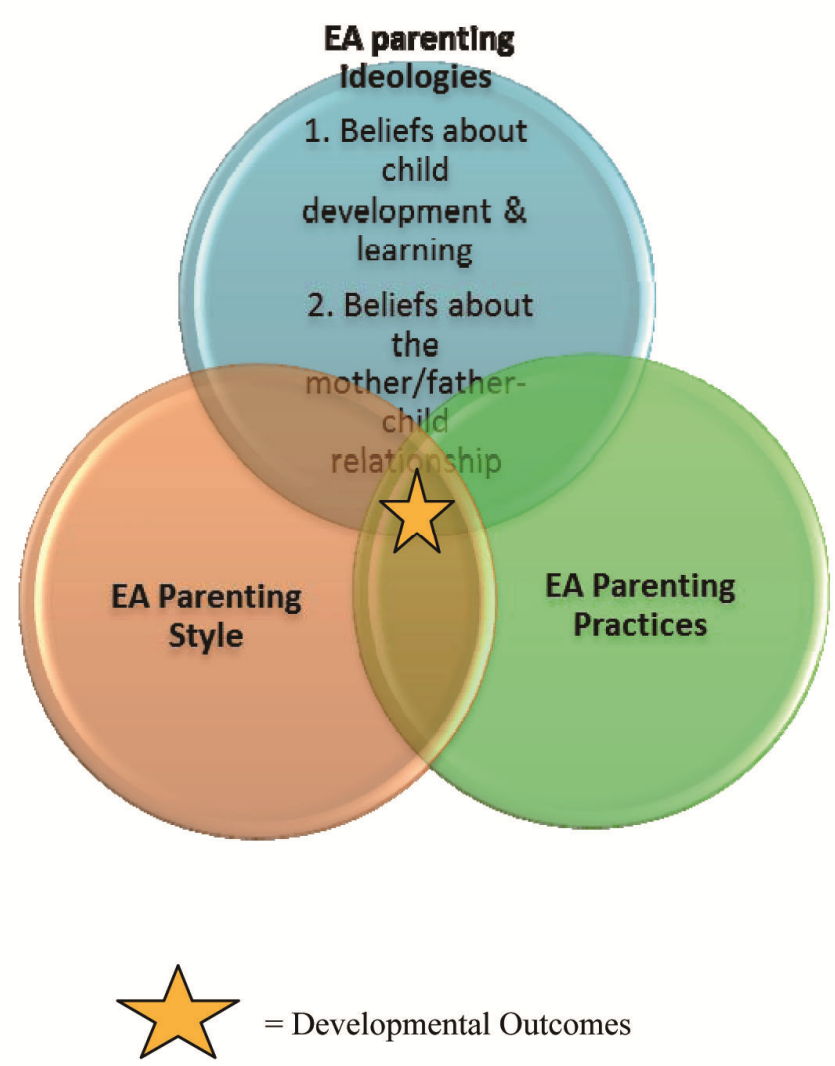

(Korean-American Academic Achievement)

Figure 1. Conceptual model of the East Asian Parenting Model (EAPM) 


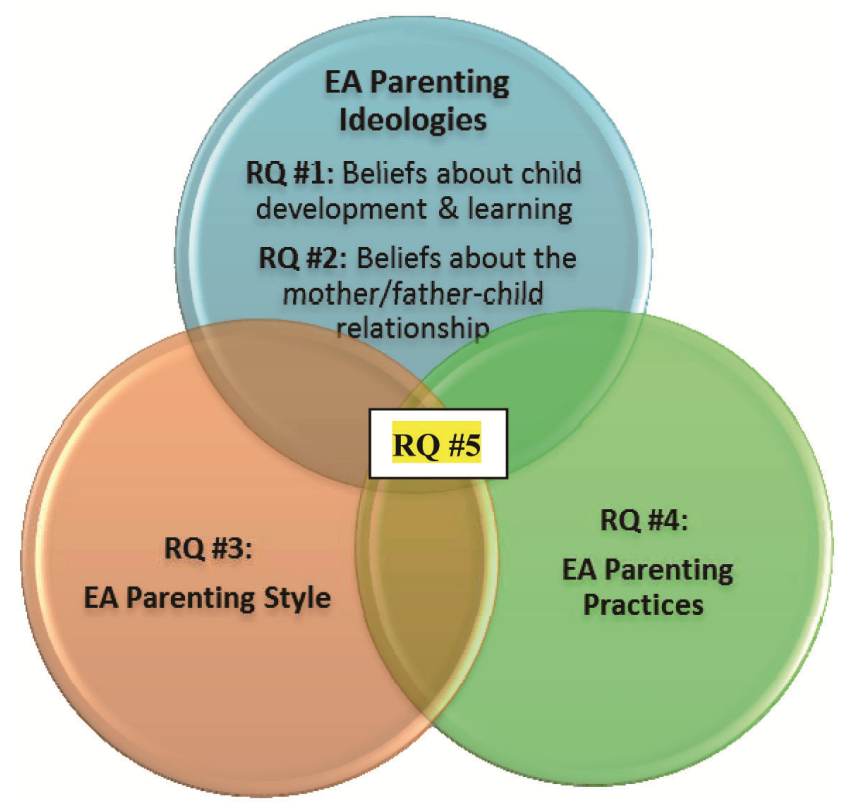

Figure 2. The East Asian Parenting Model in terms of the research questions as the constructs overlap and form an intersection of achievement for Korean-American academic success

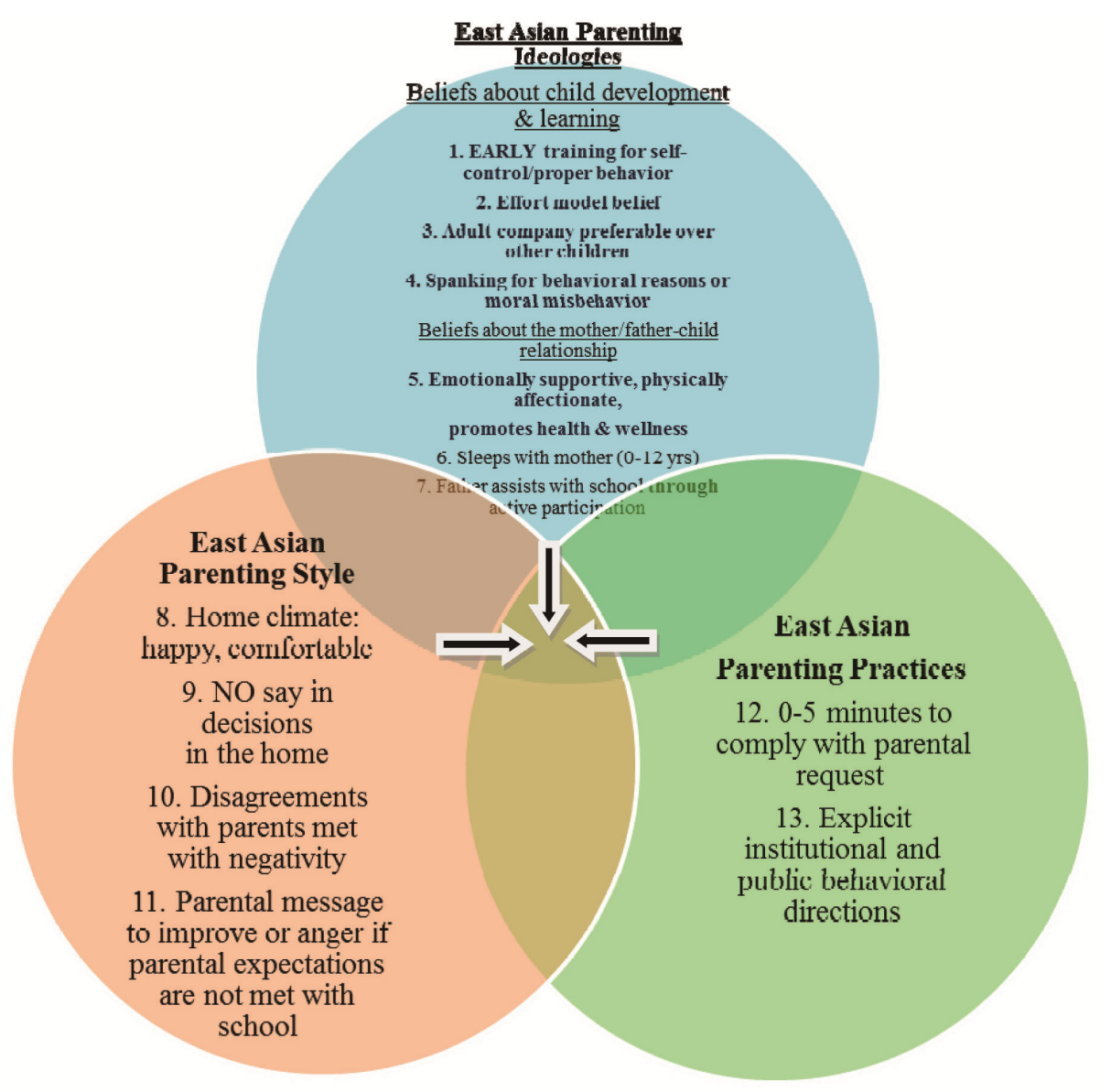

Figure 3. Student perceptions of the 13 common factors across high-achieving, Korean-American primary school students within the EAPM that form an intersection of achievement 


\section{References}

Akiba, M., \& Zhao, H. (2009). School expectations for parental involvement and student mathematics achievement: A comparative study of middle schools in the US and South Korea. Compare, 39(3), 411-428. https://doi.org/10.1080/03057920701603347

Baumrind, D. (1971). Current patterns of parental authority. Developmental Psychology Monographs, 4(1, Pt. 2). https://doi.org/10.1037/h0030372

Bong, M. (2008). Effects of parent-child relationships and classroom goal structures on motivation, help-seeking avoidance, and cheating. The Journal of Experimental Education, 76(2), 191-217. https://doi.org/10.3200/JEXE.76.2.191-217

Buri, J. R. (1991). Parental Authority Questionnaire. Journal of Personality Assessment, 57(1), 110-119. https://doi.org/10.1207/s15327752jpa5701_13

Chao, R. K. (1994). Beyond parental control and authoritarian parenting style: Understanding Chinese parenting through the cultural notion of training. Child Development, 65, 1111-1119. https://doi.org/10.2307/1131308

Chao, R. K., \& Arque, C. (2001). Extending reseqrch on the consequences of parenting style for Chinese Americans and European Americans. Child Development, 72(6), 1832-1843. https://doi.org/10.1111/1467-8624.00381

Chao, R., \& Tseung, V. (2002). The Parenting of Asians. In M. Bornstein's (Series Ed.), Handbook of Parenting: Vol. 4 Social conditions and applied parenting (2nd edition, pp. 59-93). New Jersey: Lawrence Erlbaum Associates.

Choi, Y., Kim, S., Kim, Y., \& Park, I. J. (2013). Is Asian American parenting controlling and harsh? Empirical testing of relationships between Korean American and Western parenting measures. Asian American Journal of Psychology, 4(1), 19-29. https://doi.org/10.1037/a0031220

Choi, Y., Kim, Y., Pekelnicky, D., \& Kim, H. (2013). Preservation and Modification of Culture in Family Socialization: Development of Parenting Measures for Korean Immigrant Families. Asian American Journal of Psychology, 4(2), 143-154. https://doi.org/10.1037/a0028772

Chua, A. (2011). Battle Hymn of the Tiger Mother. New York: The Penguin Press.

Coleman, J. (1966). Equality of Educational Opportunity (COLEMAN) Study (EEOS). ICPSR06389-v3. Ann Arbor, MI: Inter-university Consortium for Political and Social Research [distributor], 2007-04-27.

Creswell, J. W. (2009). Research Design: Qualitative, Quantitative, and Mixed Methods Approaches. Los Angeles: Sage.

Darling, N., \& Steinberg, L. (1993). Parenting style as context: An interactive model. Psychological Bulletin, 113(5), 48-496.

Farver, J. A., Kim, Y. K., \& Lee, Y. (1995). Cultural Differences in Korean- and Anglo-American Preschoolers' Social Interaction and Play Behaviors. Child Development, 66(4), 1088-1099. https://doi.org/10.2307/1131800

Goodenow, C., \& Grady, K. E. (1993). The Relationship of Social Belonging and Friends' Values to Academic Motivation Among Urban Adolescent Students. The Journal of Experiemental Education, 62(1), 60-71. https://doi.org/10.1080/00220973.1993.9943831

Grusec, J. E., \& Goodnow, J. J. (1994). Impact of parental discipline methods on the child's internalization of values: A reconceptualization of current points of view. Developmental Psychology, 30(1), 4-19. https://doi.org/10.1037/0012-1649.30.1.4

Grusec, J. E., Goodnow, J. J., \& Kuzcynski, L. (2000). New directions in analysis of parenting contributions to children's acquisition of values. Child Development, 71(1), 205-211. https://doi.org/10.1111/1467-8624.00135

Hong, E., Milgram, R. M., \& Perkins, P. G. (1995). Homework style and homework behavior of Korean and American children.

Kang, S. W. (2002). Democracy and human rights education in South Korea. Comparative Education, 38(3), 315-325. https://doi.org/10.1080/0305006022000014179 
Kim, U., \& Park, Y. S. (2006). Indigenous psychological analysis of academic achievement in Korea: The influence of self-efficacy, parents, and culture. International Journal of Psychology, 41(4), 287-292. https://doi.org/10.1080/00207590544000068

Koh, M. S., \& Shin, S. (2005). Korean education in cultural context. Essays in Education.

Larson, R., \& Lee, M. (2000). The Korean "Examination Hell": Long hours of studying, distress, and depression. Journal of Youth and Adolescence, 29(2), 249-271. https://doi.org/10.1023/A:1005160717081

Lee, S. (1996). Academic Achievement Among Asian Americans. In S. Lee (Ed.), Understanding the Model Minority Stereotype: Listening to Asian American Youth (pp. 52-69). New York: Teachers College Press.

Moon, B., \& Morash, M. (2004). Adaption of theory for alternative cultural contexts: Agnew's General Strain Theory in South Korea. Journal of International and Comparative Criminal Justice, 28, 77-104. https://doi.org/10.1080/01924036.2004.10855341

Morash, M., \& Moon, B. (2007). Gender differences in the effects of strain on the delinquency of South Korean youth. Youth \& Society, 38(3), 300-321. https://doi.org/10.1177/0044118X06287861

NCES. (2013). The Condition of Education 2013. Washington D.C.: U.S. Department of Education.

NCLB. (2011). No Child Left Behind. Retrieved from http://www2.ed.gov/nclb/landing.jhtml

Noyot-Corbitt, C., \& Moon, S. S. (2010). Multifaceted reality of juvenile delinquency: An empirical analysis of structural theories and literature. Child Adolescent Social Work Journal, 24, 245-268. https://doi.org/10.1007/s10560-010-0205-x

Paik, S. J. (2008). Altering the curriculum of the home: Learning environments for U.S. and Korean students. Marriage and Family Review, 43(3/4), 289-307. https://doi.org/10.1080/01494920802072504

Park, S. J. (2007). Educational manager mothers: South Korea's neoliberal transformation. Korea Journal, $187-213$.

Piaget, J. (1952). The Origins of Intelligence in Children . New York: International University Press. https://doi.org/10.1037/11494-000

Schneider, B., \& Lee, Y. (1990). A model for academic success: The school and home environment for East Asian students. Anthropology and Education Quarterly, 21(4), 358-377. https://doi.org/10.1525/aeq.1990.21.4.04x0596x

Shek, Y. L. (2006). Asian American Masculinity: A Review of the Literature. The Journal of Men's Studies, 14(3), 379-391. https://doi.org/10.3149/jms.1403.379

Shin, C. S., \& Yang, S. (2008). Parent attitudes towards education: What matters for children's well-being? Children and Ylouth Services Review, 30, 1328-1335. https://doi.org/10.1016/j.childyouth.2008.03.015

Sorensen, C. W. (1994). Success and Education in South Korea. Comparative Education Review, 38(1), 10-35. https://doi.org/10.1086/447223

Spera, C. (2006). Adolescents' perceptions of parental goals, practices, and styles in relation to their motivation and achievement. The Journal of Early Adolescence, 26, 456. https://doi.org/10.1177/0272431606291940

Steinberg, L., Lambom, S., Dornbusch, S., \& Darling, N. (1992). Impact of parenting practices on adolescent achievement: authoritative parenting, school involvement, and encouragement to succeed. Child Development, 63(5), 1226-1281. https://doi.org/10.2307/1131532

U.S. Census Bureau. (2012). The Asian Population 2010. Washington, D.C.: U.S. Department of Commerce, Economics and Statistics Administration.

U.S. Census Bureau. (2013). American Fact Finder. Retrieved from U.S. Census Bureau: www.factfinder2census.gov

Won, S. J., \& Han, S. (2010). Out-of-school activities and achievement among middle school students in the U.S. and South Korea. Journal of Advanced Academics, 21(4), 628-661. https://doi.org/10.1177/1932202X1002100404

$\mathrm{Wu}, \mathrm{D}$. (1985). Child training in Chinese culture. In W. S. Tseng \& D. Wu (Eds.), Chinese culture and mental health (pp. 113-134). Orlando: Academic Press. https://doi.org/10.1016/B978-0-12-701630-6.50016-2 
Yang, S., \& Rettig, K. D. (2003). The value tensions in Korean-American mother-child relations while $\begin{array}{lllll}\text { facilitating academic } & \text { success. Personal }\end{array}$ https://doi.org/10.1111/1475-6811.00054

Yeung, W. J. J. (2013). Asian Fatherhood. Journal of Family Issues, 34(2), 143-160. https://doi.org/10.1177/0192513X12461133

Young, N. F. (1972). Independence training from a cross-cultural perspective. American Anthropologist, 74(3), 629-638. https://doi.org/10.1525/aa.1972.74.3.02a00260

\section{Appendix A}

\section{Semi-Structured Interview Protocol: Student}

Perceptions of the East Asian Parenting Model

This interview is to be administered by the researcher in English. This interview will cover four sections. Sections I and II are derived from the concepts of chiao shun and guan: "ideologies on child development and learning" (derived from the literature on East Asian parenting) and "ideologies on the mother-child relationship" (derived from the same literature and involves such ideas as the child being in constant care of the mother). Parts III and IV cover East Asian Parenting Style and Practices questions adapted from the Parental Authority Questionnaire by Buri (1991), Darling and Steinberg's constructs of parenting style and parenting practices, and a previous pilot study conducted by the author.

Opening statement: "I am going to ask you some questions. Please respond to the following questions as you think your parents believe. Your answers can be long or short. Just answer the best you can."

Part I: East Asian parental ideologies about child development and learning (based on Chao, 1994)

1). Do your parents feel that a child should be taught as soon as possible to behave properly and have self-control? (i.e., in a restaurant or with adults)? Explain.

2). Do your parents feel that a child can improve in almost anything if they work hard? (i.e., school)? You know this how?

3). Do your parents feel that being around other adults instead of other kids helps children to behave? (i.e., with adults instead of daycare)? You know this how?

4). Under what circumstances do your parents feel that spanking a child is acceptable? (i.e., disobeying parents)?

Part II: East Asian parental ideologies about the mother-child relationship (based on Chao, 1994)

5). In what ways does your mother show her love for you?

6). Do your parents feel that only mothers should take care of the children in a family?] (i.e., making all meals, transportation arrangements, no babysitters or daycare)? You know this how?

7). Do your parents feel that mothers should sacrifice everything for a child's education? (i.e., no outside career or all money earned spent only for tutors or tuition)? You know this how?

8). How do your parents feel about children being allowed to sleep in the mother's bed? (i.e., whenever they want and/or at any age)?

9). In what ways does your father play a role in your education? (i.e., parent conferences, homework?)

Part III: East Asian parenting style (based on Buri, 1991 and Darling \& Steinberg, 1994)

10). What is the emotional climate (mood) of your home? (i.e., stressful, tense, loving)?

11). What happens when your parents make any decisions in the home which affect you? (i.e., discipline)?

12). What happens when you disagree with your parents? (i.e., house rules)?

13). What happens if you do not meet your parents' expectations for you in any given situation? (i.e., behavior or grades)?

Part IV: East Asian parenting practices (based on Buri, 1991 and Darling \& Steinberg, 1994)

14). How have your parents made you do things "for your own good"?

15). How quickly are you expected to do something when your parents ask you to do it?

16). How do your parents teach you how to behave in and outside of school? 
17). If you need something for your education (i.e., information, knowledge, calculator), and your parents cannot get it for you, how do your parents get you what you need?

\section{Copyrights}

Copyright for this article is retained by the author(s), with first publication rights granted to the journal.

This is an open-access article distributed under the terms and conditions of the Creative Commons Attribution license (http://creativecommons.org/licenses/by/4.0/). 